\title{
Development of Residence Buildings of Shanghai in Contemporary Times
}

\author{
Xiaoqing HU \\ Wuhan University, Wuhan, China
}

\begin{abstract}
KEYWORD: Residential buildings; Shanghai
ABSTRACT: Under the background of social changes of Shanghai in the contemporary times, various types of residential buildings appeared and sudden changes have been made in the living morphology. The paper explores the development process of Shanghai residence dwellings according to four historical stages and summarizes the characteristics of the living morphology of Shanghai in contemporary and Modern times.
\end{abstract}

\section{INTRODUCTION}

Shanghai is a city mainly characterized by modern city and building culture. In nearly 100 years' urban development process, it almost has included various styles of the world buildings in various periods. Meanwhile,Shanghai was also splendid in economy, culture and social life, with rich urban relics. Under the background of social changes in the contemporary and modern Shanghai, sudden change has been made in the living morphology, and various types of living different from the traditional Chinese dwellings like lanes, independent residences and multi-floor amalgamated dwellings have appeared. With the time context in this paper, the development process of Shanghai residence dwellings is sorted according to four historical stages, namely before port opening $\left(13^{\text {th }}\right.$ century to $18^{\text {th }}$ century), after port opening to the period before the founding of PRC (1840-1849), after founding of the PR to the period before the reform and opening up (1949-1978) and after the reform and opening up (1978-now).

\section{Before port opening}

Shanghai formed a town in the Southern Song Dynasty, at the beginning of the Yuan Dynasty (1292), Shanghai County was formally established, and there was quite a considerable scale at the end of the Ming Dynasty. Chapter 18 Priest Lazarus Cattaneo and Xu Baolu in Shanghai in Volume $\mathrm{V}$ of Chinese Notes by Matteo Ricci mentioned the scale and population of Shanghai city in the Ming Dynasty, "there are two feet long city walls surrounding the city, there are as many houses in suburbs as in the city, totally more than 40,000 households, generally calculated by the number of kitchen ranges. It is not surprising that there is so large a population in the Chinese cities, because even if the villages are densely populated. The surrounding area of the city is a flat highland, it seems rather to be village than a garden city, with towers and villages houses and farmlands stretching to the horizon. There are more than 20,000 households in the peripheral area, with total urban and suburb populatin more than 300,000 who are under the jurisdiction of the same city". According to the statement of Matteo Ricci and the area of Shanghai 0.825 square meter at that time, it can be estimated that the population density was 120,000 per square kilometer.

Before port opening, Shanghai was presented a typical appearance of the Yangtze River Delta riverside town. In 1841, Shanghai had a population of 410,000, about 230,000 living in the county and near the urban area, ranking the $12^{\text {th }}$ position in the nationwide cities. Most of the dwellings were of brick and wood structures with low bungalows, three or five case bays, the middle was guest house and both side were wing rooms. People of the same family lived together, and the dwellings were expended back and forth along the central axis with the increasing of family population, forming two or three depths.

With the signing of Sino-Britain Nanjing Treaty in August 1842, Shanghai became one of the five cities opened for trade, and on November 17 of the same year, Shanghai was opened to become a port. With the advantages of geographical position and convenience of policy, after port opening, Shanghai was leading in China in many aspects like science, technology, culture, industry and commerce. Sharp change was also made in the city, and Shanghai abruptly became the largest city 
in modern China and even the Far East. In such a historical background, the dwellings in Shanghai started the process of modernization.

\section{After port opening to the period before the founding of PRC}

The development of residences in Shanghai after port opening to the period before the founding of PRC is divided into the following three stages. The first stage is the formation of concession and emerging of lane dwellings (1840-1914).

After port opening, the urban population of Shanghai rapidly increased with the prosperity of economy, Shanghai had population breaking through 1 million in 1880 and up to 1.3 million by 1910 at the end of the Qing Dynasty, becoming the first large city in China far more than Beijing. The population explosion and the concession expansion in the later $19^{\text {th }}$ century brought an unprecedented demand, and for profit purpose, the form of houses built in block, rented or sold by household appeared. The early houses built with wood boards rented to the Chinese for living were in row layout. This way of construction was different from the traditional self-sufficiency residence construction, and it was the prototype of modern urban house lot industry in China.

After 1870, the concession authority banned the lane houses of simple wood boards and began to construct the lane residences of stone store type, like Xingren Lane and the later Mianyang Lane, Jixiang Lane and Dunren Lane. The rapid increasing of population made house construction for rent in the concession became an industry with extremely large industry, and most of the earliest old lane residences were built in the concession area, and later were also greatly developed in the Chinese living area. The early old-style Sikumen house absorbed the row house form of Europe, and the unit grew out of the traditional courtyard residences, with distinctive traditional Chinese architecture features in structure and form. Generally there were two floors in each building, with a living area of more than 100 to 200 square meters, appropriate for the larger family, and they had less floor area and low construction price. Around the World War I, the family structure in Shanghai was changed overall, and the old-style lanes tended to be gradually declined. At present, such residences are seldom seen in Shanghai.

The period from the end of the $19^{\text {th }}$ century to the beginning of the $20^{\text {th }}$ century witnessed the heyday of construction of lane residences, and Qianjia Lane, Xiaoyou Lane, Caojia Lane, Hejia Lane, Qinyi Lane, Qiaojia Lane, Yaojia Lane and Liujia Lane were all built in this period. Before and after the expansion of the French Concession, some real estate agents developed lane residences on both sides of the boundary-crossing road, and Yongsheng Lane, Jianye Lane, Xinmin Lane and Guangyuan Lane were successively built. The number of buildings in each lane ranged from ten to hundreds of buildings. Siwen Lane in Xinzha Road was the largest old-style lane, consisting of 700 Sikumen houses. During this period, a group of garden residences were also built, and at present, only Lilac Garden is preserved.

The second stage was the mature period of lane residences and heyday of real estate speculation (1914-1937). After the 1911 Revolution, as a port city of foreign trade, with the special position of concession, Shanghai was rapidly developed. In 1936, Shanghai had a population of 3.81 million, the public concession most densely populated, 1.189 million people lived in an area of 22.60 square meters, with population density up to 52255 persons per square kilometer. In addition to the deformed development of the old urban area and old concession area, the zones in Zhabei, Nanshi, Huxi and Pudong had also been gradually developed into urban area and civilian living area.

The 1920s and 1930s saw the first climax of construction of modern residences in Shanghai, a group of dense lanes and a lot of garden villas were successively built. From 1919 to 1931, 65,000 various commercial houses had been built in the public concession. The lane residences, apartment residences and garden residences with construction area of about 23 million square meters built from the end of the $19^{\text {th }}$ century to the 1930 s became the most characteristic building type in Shanghai.

The lane residences in this period had the largest construction volume, on the basis of the oldstyle Sikumen in the $19^{\text {th }}$ century, the new Sikumen lanes, new lanes, garden lanes and apartment lanes were developed. The new stone store gate lanes were evolved from the old style, mainly constructed to the buildings with two floors, and the number of living rooms was reduced to adapt to the demand of decomposition of large families and emerging of small ones. The new lane residences appearing later emphasized the further clear division of the use function, there were 
living rooms, bedrooms, kitchens, bath rooms, sanitary equipment and gas furnaces, and there was a small courtyard in front of the dwelling, and the building appearance more tended to be the western style, suitable for the rich civilian levels. The earliest new lane residence was Albert Lane (now Lane 582, South Shaanxi Road) by China Construction Company in 1920. Most of the new lanes were built from 1925 to 1939, and most of them were distributed in the public concession and the central area of French Concession. Dade Lane, Dafu Lane, Xinde Lane, Hequnfang, Xingye Lane and Shude Lane were all built during this period. After the founding of the PRC, most of the new lanes were preserved and basically maintained original.

After the 1930s, a new living form appeared, namely the multi-floor amalgamated dwelling (apartment), most prevailing in the French Concession, which could be divided into two types, one was the multi-floor apartment stores, 4-5 floors and the other was high-rise, up to dozens of floors. A group of senior garden residences also appeared in this period. The garden residences (including garden lane residences) were developed and distributed from east to west along Nanjing Road, Yan'an Road and East Huaihai Road with the expansion of concession. Another type was the lane garden, mainly characterized by the fact that the garden residences above two floors were connected together to form lane, with less floor area and building area. Such kind of residences were constructed from 1920 to 1949.

The third stage was the period from "isolated island prosperity" to comprehensive deterioration of living condition (1937-1949).

On November 11, 1937, the Japanese army occupied the whole Shanghai except the concession. After occupation, the concession became an "isolated island", more prosperous than before the war. Large area of new lane residences, garden lane residences, independent residences, multi-floor amalgamated dwelling and other high-grade residence appeared. After the breakout of the Pacific War in 1941, the history of concession came to the end. The invasion of the Japanese army greatly damaged the city of Shanghai. In "January 28 Incident" and "August 13 Incident", a lot of houses in Zhabei, Hongkou and Nanshi etc. were destructed and the refuges swarmed into the shanty town. On the eve of liberation of Shanghai, there were 322 shanty towns with more than 200 households. $^{[1]}$

According to the statistics in 1949, the living room area in Shanghai was 2359.4 square meters (converted into living area 1610.8 square meters), population was 4.141 million (not including the suburb population) and average living area 3.9 square meters, in which the area of the old lanes and shacks was 15.63 million square meters, accounting for $66.2 \%$ of the living house building area in the whole Shanghai. There were totally 197500 shacks, with a building area 3.228 million square meters and population 1.15 million. The residents' living conditions were polarized, the ordinary civilians had very difficult living condition and $60 \%$ of the civilians had poor living condition.

\section{After port opening to the period before the founding of PRC}

The residence development after the founding of the PRC to the period before the reform and opening up was divided into the following two stages. The first stage was the emerging of the new worker village (the 1950s).

The industrialization process started from the 1950s made Shanghai become the first largest industrial city in China. The living development in the urban area was dominated by the northward expansion, so as to form the urban spatial pattern of "dominated by the north-south axis, with the west-east direction as the auxiliary" to correspond to the industrial development. The residence construction in this stage was mainly the construction of public residence areas. With the development of industry, new worker village was started to be built in the suburb in a planned manner and large scale. In the beginning of the 1950s, 9 new residence villages including Kongjiang, Changbai, Fengcheng, Anshan, Ganquan, Tianshan, Rihui, Changhang and Caoyang were planned and constructed in the industrial intensive areas in the west and south of Shanghai. This Group of new residence villages had a floor area 12783ha, including 21830 residence units, with building area 600,040 square meters, living area 278,500 square meters (gross plot ratio 0.47 ) and scale of 20000 to 30000 persons in each new village. By the end of 1958, there had been totally 201 new villages constructed surrounding the edge of the urban area. By 1960, totally 5 million square meters of new worker villages had been built. 560,000 square meters of residences were newly built every year on average from 1950 to 1960, but due to the increase of urban population 
with the development of industrialization, the housing construction could not keep up with the increasing of population, the per capita living area declined from $3.9 \mathrm{~m}^{2}$ in 1949 to $3.1 \mathrm{~m}^{2}$ in 1957 , and rose to $3.7 \mathrm{~m}^{2}$ in 1959 , with a highlighted contradiction of residence urgency.

The second stage was the Cultural Revolution during which the development was suspended (in the 1960s and 1970s).

The 1960s and 1970s saw the extremely difficult development of politics and economy in China, and the residence construction in Shanghai was developed slowly in such an overall context. The average completed residence area in the $1960 \mathrm{~s}$ was $460,000 \mathrm{~m}^{2}$ on average, lower than the absolute value in the $1950 \mathrm{~s}$, and rose in the $1970 \mathrm{~s}, 980,000 \mathrm{~m}^{2}$ every year on average. The residence construction in this period included the construction of public residence area and the local reconstruction of old urban area, and the radial spatial morphology of urban construction had been quite highlighted, and the expansion of living area was mainly concentrated inside the original completed area. In order to cooperate with the gradual expansion of the urban area and the opening of suburb industrial area, dozens of new villages including Pengpu New Village, Tianlin New Village and Hudong New Village had been successively completed. Compared with the new villages in the 1950s, the standard had been improved, with number of floors increasing to 4-6 floors. In the construction of satellite towns, in cooperation with the construction of large stateowned enterprises, the construction of residence areas in 7 satellite towns including Jinshanwei and Jiading was completed. The experiment of high-rise buildings was started, and some new types of residences appeared, like the small-area complete residence of independent household.

During the 30 years from 1949 to 1979 , although the urban GDP increased by 6.7 times, the urban residence construction was developed rapidly. Until 1979, the total area of the shacks with poor condition was 5.40 million square meters, accounting for $10.7 \%$ of the total residence building area; the construction area of old lanes with poor condition and non-residence building transformed into buildings was 18.75 million square meters, accounting for $4.5 \%$; and the new built residence area was 12.29 square meters, no less than $30 \%$. According to a housing investigation in 1982, $47.6 \%$ of the houses in Shanghai had various housing problems, like worn-out house structure, lack of infrastructures, several generations living in the same room and crowded living. According to the statistics, there were 70,000 households with per capita living area less than 2 square meters in Shanghai in $1980 ; 25.1 \%$ of the urban families must live together with parents and relatives, causing the actual no-house households and leading the great appearing of urban shacks. The limited housing condition made people have to accept the reality of crowdedness, and in some streets, the population density was up to 290,000 per square kilometers.

\section{After the reform and opening up}

The residence development in Shanghai after the opening up was divided into the following two stages. The first stage was the beginning of the reform and opening up (the 1980s).

From 1984, the use right of state-owned land was allowed to be transferred and circulated with payment in a certain period. The development of residences entered the transition period, the reform of public welfare house system was started, the residence construction was transformed from the single planned system to the combination of planning and market, and a large scale of unit house construction and housing market aimed at the units and civilians appeared. The residence construction in Shanghai welcomed another climax. From 1979 to 1989, 43.68 million square meters of residences were completed, accounting for 715 of the total newly built residences since 1949. Most of the residence communities constructed in this period were of combination of highrise residences with multi-rise residences. The high-rise residences in this period grew rapidly, and about 500 high-rise residence buildings were newly completed, with a total construction area of 6 million square meters. Around 1985, the construction of tower high-rise residences was started, with number of floors increasing from 12-15 to 15-33, and the average household area increased accordingly.

The residence construction in this period included the construction of public, collective and private residence areas in the remote suburb and the pushing-type reconstruction in the city. At the beginning of 1980, Shanghai has adopted the single center strategy, and the development of most of the living spaces was centered on the layout within the internal ring and development toward the suburb. The new residence villages was of discontinuous ring distribution in cluster mode along the 
outside of the internal ring, and was alternated with the industrial land. 74 residence areas and residence communities were developed in the central urban area from 1980 to 1990, with a residence construction area of 39.13 million square meters. The construction scale of large residence areas led by the government was increased, like Quyang New Village, Langjian New Village and Changbai New Village, with living scale ranging from 50,000-60,000 to more than 100,000 square meters, and the construction area was about 1 million square meters; and the commercial residence areas in Gubei New District etc. were sold.

The reconstruction of the old area was comprehensively carried in the 1980s, and 7-year central area old housing reconstruction plan from 1984 to 1990 was prepared, involving in 23 regions, with a floor area of 414,000 square meters. In the 1980 s, totally 3.31 million square metes of residence construction areas were demolished and 138,000 households of residents were moved. Because of large-scale municipal construction and population migration in the old urban area, the number of permanent residents reduced. The shanty towns and other lane residence areas in the old urban areas were corroded by the industrial, municipal and commercial services, and a lot of residence lands within the internal ring of the city were transformed into other types. In this stage, the living space in Shanghai formed a pattern of mixing of peripheral ring expansion and internal crushing.

The second stage was the period of development of Pudong and opening of real estate market (the 1990s to now)The opening up of Pudong in 1990 established the status of economic, financial and trade center of Shanghai. After the stop of construction of welfare houses in 1999, the commercial residences became the main body of residence construction. Table 6.1 lists the commercialization process of housing development in Shanghai. The development of commercial residences in Shanghai is roughly divided into five stages, the starting stage (before 1993), advancing stage (1994 to 1998), comprehensive implementation stage (1999 to 2003), rapid development stage (2003 to 2007) and passive adjustment period (from 2008). ${ }^{[2]}$ The commercial residences in this period mainly included high-rise residences, small high-rise residences, multi-rise residences, row residences and independent residences, and the ultrahigh-rise residence up to 60 floors like Shimao Riverside Garden appeared.

The 1990s was another peak period of residence land use expansion in the central urban area of Shanghai after the 1950s. The expansion of residence land was spread in each direction of the urban construction area, and the expansion scale increased rapidly. The living construction area increased year by area, increasing by 48.42 million square meters accumulatively from 1993 to 1997, with an increase rate of $42 \%$. After 2001, under the condition of sharp increasing of residence demands, the construction volume of residences reached an unprecedented scale. By 2004, the completed residence area was up to 32.7 million square meters, with per capita living area in the urban area increasing to 14.8 square meters. From 2003 to 2007, the proportion of real estate investment of Shanghai in GDP was more than $10 \%$, in which the proportion of residence investment was more than $65 \%$, and this reflected that the real estate industry had become a pillar industry in the economic development of Shanghai to a certain extent.

In 1992, Shanghai municipality proposed " 365 " project, i.e. by the end of the $20^{\text {th }}$ century, to complete the construction of 3.65 million square meters of shanty towns and shacks, with complete residence rate up to $70 \%$. The commercial residence land and municipal and commercial service lands in the central urban areas replaced the industrial land, shanty towns and some lane residences in the old town, several shanty clusters surrounding the old urban areas were reduced to scattered plots. 23.3 million square meters of old residences were demolished from 1991 to 1998, totally 540,000 households. Through land lease approval, old area reconstruction , joint construction, reduction of the secondary industry and development of the ternary industry and relocation of polluting enterprises, the residence construction in the central urban area had been developed rapidly. The newly built residences in the central urban area was dominated by high-rise residences, the newly built high-rise residences were adjacent to the original lane residences and the urban residence space presented a mosaicked trend. After 1992, the residences in the suburb (especially Pudong New District and Minhang District) had been developed rapidly. The development of largescale commercial residences between the internal and external rings formed several living blocks, presenting a finger-shape extension between the industrial areas, connecting to pieces mutually and forming a ring layer filling in the peripheral living area. The great development of commercial residences in Pudong New District in the 1990s made the living space transformed into four- 
direction expansion from the development concentrated in Puxi. With the expansion of urban scale, the pattern of living area has evolved into complicated comprehensive mode of section, ring and cluster from the single central ring structure, and presented a trend of development to the multicenter structure. layout of residence land was extended to the surrounding area of external ring with the adjustment of function of central urban area and development of urban traffic. In 2004, Shanghai Municipal Government approved the printing and issue of Planning Outline on Practically Promoting "Three Concentrations" and Accelerating Suburb Development of Shanghai and proposed the three-level system of "new city-new town-central city". The planning and construction of towns and living system play a great promotion role for the development of living space in the suburb of Shanghai.

\section{Reference}

[1]Caoshu,Wushiwei.The role of economic factors in the detail planning. The Annual Conference of Chinese Planning,2007

[2]Chenchangyong.The status and strategies of residential density of Guangzhou.The $5^{\text {th }}$ Seminar of Chinese Urban Housing 